\title{
El Sistema de Responsabilidad Penal para Adolescentes (SRPA) en el ordenamiento jurídico colombiano ${ }^{1}$
}

\author{
The Sistema de Responsabilidad Penal para \\ Adolescentes SRPA (Criminal Responsibility System for \\ Adolescents) in Colombia's legal system
}

\author{
Héctor Fabio Velasco Hernández \\ Magíster en Derecho Público \\ Universidad Pontificia Bolivariana-Seccional Palmira, Colombia \\ Grupo de Investigación en Derecho (GRID) \\ Correo electrónico: hector.velasco@upb.edu.co \\ https://orcid.org/0000-0002-5652-6947
}

\section{Resumen}

El Sistema de Responsabilidad Penal para Adolescentes-SRPA, fue creado por la ley 1098 de 2006 en su libro segundo, se entiende como un conjunto de normas, procedimientos e instituciones especiales, que tiene por finalidad atender al adolescente en conflicto con la Ley Penal. Su desarrollo en el contexto jurídico colombiano hace que su estudio y análisis sea relevante para la comprensión de un sistema de justicia relativamente nuevo en Colombia. El presente artículo tiene el propósito de exponer su origen en el marco jurídico colombiano, la importancia de la justicia restaurativa para el SRPA, entidades que lo conforman, fases de implementación y los

1 El presente artículo hace parte de uno de los capítulos del proyecto de investigación "Adolescente Infractor en el Municipio de Palmira", adelantado en la Universidad Pontificia Bolivariana-Seccional Palmira. 
problemas que afronta en la actualidad. Para esto, se propone revisar el caso del municipio de Palmira, como un referente de la problemática que conlleva la puesta en marcha del sistema.

\section{Palabras clave}

Niños, niñas, adolescentes, legislación colombiana, normas internacionales, justicia restaurativa, Sistema de Responsabilidad Penal para Adolescentes-SRPA.

\section{Abstract}

The Sistema de Responsabilidad Penal para Adolescentes-SRPA, created by Ley 1098 (Law 1098) on its second book, is understood as a set of rules, procedures, and special institutions, which are intended to deal with adolescents in conflict with Criminal Law. Its development within the Colombian legal context makes its study and analysis relevant to the understanding of a relatively new justice system in Colombia. This paper has the purpose of exposing its origins in Colombia's legal framework, the importance of restorative justice for the SRPA, the entities that comprise it, the stages of implementation, and the problems it currently faces. To this end, the revision of the Municipio de Palmira case is proposed, as a benchmark of the difficulties that the implementation of the system entails

\section{Keywords}

Boys, girls, adolescents, Colombian legislation, international norms, restorative justice, Sistema de Responsabilidad Penal para Adolescentes-SRPA.

\section{Introducción}

El artículo 44 de la Constitución Nacional (Const., 1991, art. 44) establece que la familia, la sociedad y el Estado tienen la obligación de asistir y proteger al niño en su desarrollo armónico integral y en el ejercicio pleno de sus derechos. El artículo 45 (Const., 1991, art. 45) señala los derechos del adolescente a su protección y formación integral. Frente a lo anterior, es menester precisar que la Constitución consagra en los artículos 44 y 45 (Const., 1991, art. 44 y 45) de forma separada los derechos de los niños y adolescentes, lo que haría pensar que tienen protección distinta. Al respecto el Alto Tribunal Constitucional mediante sentencia C-740 de 2008 se pronunció así:

\footnotetext{
Cómo citar este artículo:

Velasco, H. F. (2020). El Sistema de Responsabilidad Penal para Adolescentes (SRPA) en el ordenamiento jurídico colombiano. Revista de la Facultad de Derecho y Ciencias Políticas, 50 (133), pp. 259-280. doi: http://dx.doi.org/10.18566/rfdcp.v50n133.a02

Recibido: 31 de mayo de 2019.

Aprobado: 27 de abril de 2020.
} 
En relación con la protección constitucional a los adolescentes, la Corte Constitucional ha considerado que ellos están comprendidos en el concepto amplio de "niños" de que trata el Art. 44 de la Constitución y por tanto gozan de protección especial por parte de la familia, la sociedad y el Estado y son titulares de los derechos fundamentales en él consagrados, que prevalecen sobre los derechos de los demás. (Sentencia C-740 de 2008)

Así las cosas, la categoría jurídica que se va a tratar en el transcurrir del artículo será la de adolescente, dada su vinculación legal y antecedente jurisprudencial comprendido en el concepto amplio de niño, gozando de las mismas garantías fundamentales expuestas por el texto constitucional.

Diferentes tratados internacionales, como la Convención de los Derechos del Niño de 1989 (ONU, 1989), las Reglas mínimas de las Naciones Unidas para la Administración de Justicia de Menores "Reglas de Beijing” (1985), entre otras, fijan parámetros específicos que obligan a los Estados a disponer de un marco normativo e institucional para atender al adolescente en conflicto con la Ley penal, a través de un sistema especializado. Su origen, trascendencia y problemas de implementación en el ordenamiento jurídico colombiano a partir de la ley 1098 de 2006 (ley 1098, 2006), sus modificaciones y lineamientos administrativos dictados por el ejecutivo hacen de su estudio una necesidad para su comprensión. Esto debido a su importancia en la práctica, ya que en muchas ocasiones tiene resultados desfavorables para los adolescentes, carentes de la efectiva protección integral.

Cabe mencionar que el presente artículo se presenta como resultado del proyecto de investigación “El Adolescente Infractor en el Municipio de Palmira”, realizado en el seno de la Universidad Pontificia Bolivariana- Seccional Palmira, se espera sea fuente de información para la academia y la institucionalidad.

\section{Antecedente y marco jurídico del Sistema de Responsabilidad Penal para Adolescentes- SRPA}

La ley 599 de 2000 (ley 599, 2000), por la que se expide el Código Penal, en su Artículo 33 inciso tercero establece: "Los menores de dieciocho (18) años estarán sometidos al Sistema de Responsabilidad Penal Juvenil” (Código penal, 2000, art. 33, inciso 3). Este inciso fue objeto de revisión 
constitucional por parte de la Corte Constitucional, declarado exequible mediante Sentencia C-839 de 2001 (Sentencia C-839 de 2001). El argumento central de revisión giró en determinar si el Sistema de Responsabilidad Penal Juvenil, es violatorio de los derechos fundamentales de los niños, caso que en ese entonces llevó al Alto Tribunal a realizar un análisis de las diferentes normas internacionales, como son: los pactos internacionales, derechos civiles y políticos (1966) y derechos económicos, sociales y culturales (1966), Reglas mínimas de las Naciones Unidas para la administración de justicia de menores (1985), Reglas de las Naciones Unidas para la protección de los menores privados de la libertad (1990), Directrices de las Naciones Unidas para prevención de la delincuencia juvenil “Directrices de la RIAD” (1990) De igual forma, observar la vinculación de los mencionados instrumentos a la carta fundamental, en virtud del artículo 93 (Const., 1991, art. 93) o bloque de constitucionalidad. La Corte concluye que la instauración de un sistema especial no es violatorio de los derechos prevalentes del niño, que la comunidad internacional lo legitima, respetando el marco de garantías procesales en favor del adolescente que el mismo exige. Es decir:

La institucionalización de una justicia de menores no constituye, per se, un atentado contra los derechos de los menores, ni va en detrimento del deber de protección que recae en la sociedad y el Estado. Antes bien, podría decirse que la comunidad internacional ha reconocido ampliamente la necesidad de crear un sistema judicial especializado que permita resolver el problema de la delincuencia juvenil desde la perspectiva de la resocialización, la tutela y la rehabilitación, evitando que el menor desvíe su proceso de adaptación y trunque su desarrollo físico y moral, base del desarrollo de la sociedad moderna. Mientras la ley se ajuste a los principios constitucionales que guían el juzgamiento de los menores y conserve los objetivos que marcan su derrotero, la existencia misma de esta jurisdicción no merece reproche de constitucionalidad alguno; por el contrario, ésta debe ser avalada como el mecanismo propicio para armonizar los derechos de los menores infractores y la conservación de la seguridad pública. (Corte Constitucional, SC-839 de 2001).

Se puede observar como antecedentes del SRPA, además del Código Penal Colombiano y la sentencia de exequibilidad de la Corte Constitucional, los diferentes instrumentos internacionales, en tanto soporte fundamental para la implementación del sistema en la jurisdicción colombiana. Frente al particular, se encuentran los artículos 37 y 40 de la Convención sobre los Derechos del Niño al referir: 
En cada jurisdicción nacional se procurará promulgar un conjunto de leyes, normas y disposiciones aplicables específicamente a los menores delincuentes, así como a los órganos e instituciones encargados de las funciones de administración de la justicia de menores, conjunto que tendrá por objeto:

(a) Responder a las diversas necesidades de los menores delincuentes, y al mismo tiempo proteger sus derechos básicos;

(b) Satisfacer las necesidades de la sociedad;

(c) Aplicar cabalmente y con justicia las reglas que se enuncian a continuación. (Convención sobre los Derechos del Niño, 1989, art. 37 y 40)

La necesidad de tener una administración de justicia especialmente para los adolescentes, con normas, procedimientos e instituciones propias para su desarrollo y coherente con los instrumentos internacionales fue en parte el resultado de expedir la ley 1098 de 2006 (ley 1098, 2006), disposición que no solo creó el SRPA en el libro segundo, sino que definió su concepto, finalidad, financiación y formulación de políticas públicas que sirvan de garantía para su sostenibilidad.

La ley 1450 de 2011 Plan Nacional de Desarrollo 2010-2014, en su artículo 201 (ley 1450, 2011, art. 201) refirió que, en desarrollo del principio de corresponsabilidad y protección integral de los adolescentes, el gobierno nacional con el concurso de los gobiernos territoriales darán prioridad al SRPA, al ampliar la cobertura del sistema, a través de la construcción de centros de atención especializada e internamiento preventivo.

Posteriormente se expide el Decreto 1885 de 2015 (Decreto 1885, 2015), Por el cual se crea el Sistema Nacional de Coordinación de Responsabilidad Penal para Adolescentes- SNCRPA y se dictan otras disposiciones. Este establece una conformación del sistema nacional y departamental, sus funciones y el apoyo técnico para la puesta en marcha del mismo. Pese a todas las disposiciones creadas para su buen funcionamiento, existen falencias en su implementación: la poca voluntad estatal en la operación del sistema impide crear herramientas eficaces de prevención; la falta de centros especializados cuya misión principal sea la resocialización, hacen del hacinamiento en los pocos centros un problema central. A lo anterior se suma la congestión judicial, creada por actuaciones administrativas del Consejo Superior de la Judicatura, problemática vigente que se abordará más adelante. 
Igual relevancia tienen los lineamientos técnicos proferidos por el Instituto Colombiano de Bienestar Familar, con respecto a la operatividad del sistema, en el presente artículo referimos algunos:

Resolución No.1301 de 2010, Por la cual se aprueba el lineamiento técnico administrativo para la atención de los adolescentes en el Sistema de Responsabilidad Penal para Adolescentes (Resolución 1301 de 2010).

Resolución No. 3741 de 2011, Por la cual se modifica el lineamiento técnico administrativo para la atención de los adolescentes en el Sistema de Responsabilidad Penal para Adolescentes (Resolución 3741 de 2011).

Resolución No. 4594 de 2009, Por la cual se aprueba el lineamiento técnico administrativo para la atención de niños, niñas y adolescentes menores de catorce (14) años que se presuma o hayan incurrido en la comisión de un delito (Resolución 4594 de 2009).

Resolución No. 3454 de 2011, Por la cual se establece el marco pedagógico para los servicios de atención del Sistema de Responsabilidad Penal para Adolescentes (Resolución 3454 de 2011).

Resolución No. 1522 de 2016, Modificado por la Resolución No. 14610 de 2018, Por la cual se aprueba el lineamiento técnico modelo de atención para adolescentes y jóvenes en conflicto con la ley - SRPA (Resolución 1522 de 2016).

Resolución No. 1512 de 2016, Por la cual se aprueba el lineamiento técnico de medidas complementarias y/o de restablecimiento en administración de justicia (Resolución 1512 de 2016).

Resolución No. 1521 de 2016, Por la cual se aprueba el lineamiento técnico de servicios para medidas y sanciones del proceso judicial (SRPA) (Resolución 1521 de 2016).

Resolución No. 5668 de 2016, Por la cual se modifica el lineamiento técnico modelo de atención para adolescentes y jóvenes en conflicto con la ley - SRPA aprobado mediante Resolución 1522 del 23 de febrero de 2016 (Resolución 5668 de 2016).

Resolución No. 5666 de 2016, Por la cual se modifica el lineamiento técnico de servicios para medidas y sanciones del proceso judicial SRPA aprobado mediante Resolución 1521 del 23 de febrero de 2016 (Resolución 5666 de 2016).

Los lineamientos técnicos sirven en muchos aspectos de guía para la aplicación del sistema por parte de las diferentes instituciones públicas y privadas en tanto operadores. En ocasiones, por su contenido se convierten en manuales de contratación, indispensables para su desarrollo y el cumplimiento de la finalidad del SRPA. 


\section{Justicia Restaurativa}

Existen diferentes consideraciones en el mundo frente al modelo de justicia restaurativa resaltan su importancia como finalidad del SRPA. Alejarse de la acepción de la justicia retributiva, en tanto busca como única forma castigar el delito a través de la pena, es una consideración no concebible para el tratamiento del adolescente infractor. Por tal razón, las medidas para aplicar a los mismos desde la justicia restaurativa deben ser pedagógicas, especiales y diferenciadas en el marco de la protección integral.

En consecuencia, es apremiante el siguiente aporte: "El enfoque de la justicia restaurativa es cooperativo. No le interesa abstractamente el derecho violado, sino el hecho concreto que una persona fue lesionada por las acciones ilícitas de otra, y es el daño el que debe ser reparado” (CONPES 3629 de 2009).

En el antecedente normativo en Colombia, se puede observar un elemento de resaltar frente a las prácticas de justicia restaurativa, que posiblemente abrió la discusión en la formulación del modelo que actualmente existe en la Ley 1098 de 2006 (Ley 1098, 2006), tal antecedente normativo se presenta en la Ley 906 de 2004, Título VI, justicia restaurativa, artículo 518:

Se entenderá por programa de justicia restaurativa todo proceso en el que la víctima y el imputado, acusado o sentenciado participan conjuntamente de forma activa en la resolución de cuestiones derivadas del delito en busca de un resultado restaurativo, con o sin la participación de un facilitador. Se entiende por resultado restaurativo, el acuerdo encaminado a atender las necesidades y responsabilidades individuales y colectivas de las partes y a lograr la reintegración de la víctima y del infractor en la comunidad en busca de la reparación, la restitución y el servicio a la comunidad. (Ley 906, 2004, art. 518)

La ley referida habla de mecanismos de justicia restaurativa, sobre el particular, se expresa en el artículo 521: "Son mecanismos de justicia restaurativa la conciliación pre-procesal, la conciliación en el incidente de reparación integral y la mediación” (Ley 906, 2004, art. 521). En virtud de lo dispuesto, la justicia restaurativa busca restablecer la relación de la víctima con el infractor para permitir que el último tome conciencia del acto ilícito y repare el daño causado. De este modo, se convierte en un modelo alternativo y complementario de la justicia ordinaria, la cual limita este tipo de actuaciones, al buscar como esencia el castigo por la conducta punible. 
Según Marshall (1998) justicia restaurativa es: "un proceso a través del cual las partes involucradas en un determinado delito resuelven colectivamente cómo lidiar con las consecuencias de la ofensa y sus implicaciones para el futuro" (Marshall, 1998, p.14). La relación entre los actores colectivamente, víctima e infractor tiene la finalidad de reincorporarlos a la sociedad en el contexto comunitario, con mayor relevancia si el sujeto infractor o víctima es un adolescente.

La Corte Constitucional en Sentencia C-979 de 2005 manifiesta frente a la justicia restaurativa como un modelo transversal lo siguiente:

Desde una perspectiva sicológica se destaca que, en este modelo, esa mirada al pasado orientada a escudriñar la culpa del ofensor, propia de los esquemas retributivos, es desplazada por una visión de futuro anclada en el propósito de búsqueda de mecanismos mediante los cuales se propicie que el ofensor se enfrente con sus propios actos y sus consecuencias, adquiera conciencia acerca del daño que ocasionó, reconozca y asuma su responsabilidad e intente la reparación del agravio. En consecuencia, no es un enfoque basado en los merecimientos, sino en las necesidades emocionales, relacionales y reparatorias de las personas involucradas en el conflicto. (Sentencia C-979 de 2005)

Partiendo del análisis de la sentencia C-979 de 2005 (Sentencia C-979 de 2005), debate constitucional producto de la demanda de algunos artículos de la ley 906 de 2004, en especial el artículo 521 (ley 906, 2004, art. 521) ya referenciado. Tal lineamiento jurisprudencial se convierte en un punto de partida para el estudio y adopción en la legislación colombiana del modelo de justicia restaurativa. Antecedentes de relevancia estudiados en la providencia, la Resolución No. 2000/14 del Consejo Económico y Social de las Naciones Unidas (Resolución 2000/14 de 2000) con respecto a los principios básicos para los programas de justicia restaurativa en lo penal, el estudio abordado por el conjunto de expertos creado por la resolución, profesionales que elevaron un documento de recomendaciones y retos de aplicación de la justicia restaurativa en los diferentes Estados y que se convierte en una herramienta de interpretación para los administradores de justicia (Corte Constitucional, SC-979 de 2005).

En la discusión constitucional, se aborda la capacidad legal de la Fiscalía General de Nación de reglamentar los criterios de aplicación de los mecanismos de justicia restaurativa y si la misma es inconstitucional al invadir 
la función reglamentaria del Presidente de la República. De tal consideración, cabe resaltar las bondades de los elementos internacionales que soportan el modelo de justicia restaurativa y la necesidad de dotar de los elementos administrativos y presupuestales para la aplicación en el ordenamiento jurídico colombiano. Sistema que, por experiencia, demuestra ser más económico y efectivo en restablecer los derechos de las partes intervinientes en el conflicto que el sistema penal ordinario (Corte Constitucional, SC-979 de 2005).

De igual forma, los criterios de la justicia restaurativa equivalentes a comprender el significado del programa, proceso, resultado, partes y facilitador de la justicia restaurativa nutren el ejercicio de análisis para su aplicación por parte de las autoridades. Así, el modelo restaurativo como figura complementaria del sistema ordinario deja ver las deficiencias de la justicia penal, la cual observa la sanción al delito como única retribución, diferente al sistema restaurativo que tiene por fin establecer el diálogo entre la víctima y el infractor, restablecer la relación, reparar el daño y vincularlos a la comunidad.

Los mecanismos de justicia restaurativa descritos en el Código de Procedimiento Penal, si bien es cierto son la puerta de entrada para el SRPA, establece diferencias sustanciales en su aplicación a los adolescentes. La conciliación pre-procesal, mediación e incidente de reparación integral, reflejados en el procedimiento penal ordinario, tienen un desarrollo distinto al proceso especial para adolescentes infractores. De la misma manera, la reglamentación en el sistema penal para adultos atiende a las decisiones administrativas del Fiscal General de la Nación y para los adolescentes a los criterios del ICBF como ente coordinador del Sistema Nacional de Bienestar Familiar-SNBF.

En el caso especial de los adolescentes que infringen la ley, la Declaración de Lima sobre Justicia Juvenil Restaurativa (2009) trae consigo materias apremiantes y de consideración por parte de los Estados. La preocupación de los diferentes órganos internacionales que protegen los derechos de la infancia y adolescencia, tiene su origen en la aplicación prevalente de medidas de justicia ordinarias sobre las adoptadas para restablecer los derechos. Así, la Declaración de Lima sobre Justicia Juvenil Restaurativa expone una serie de recomendaciones sobre la aplicación del modelo de justicia restaurativa juvenil, aspectos importantes para tener un contexto legislativo que sirva 
de base para la formulación de la política pública sobre la materia, con el objetivo de permitirle al modelo ser estable y permanente. Ella surge como una recomendación capital, se trata de generar el deber de los entes internacionales (tales como Unicef, Grupo Interinstitucional sobre Justicia Juvenil, Consejo Económico y Social de la ONU) a incrementar sus esfuerzos para proporcionar asistencia técnica a los Estados que se encuentren en introducción y en dificultades de operación de los programas de justicia restaurativa (Declaración de Lima sobre Justicia Juvenil Restaurativa, 2009).

En las deliberaciones de la Declaración de Lima sobre Justicia Juvenil Restaurativa (2009) trazadas en el documento, la justicia juvenil restaurativa no puede limitarse a una etapa particular del proceso sino que debe aparecer en todas como medidas alternativa o adicional, con que se hace especial énfasis en la prevención de los delitos, su intervención no hace excepción frente a la gravedad del delito — como sí sucede para los adultos — , se aplica para toda clase de ilicitud legal, no atiende a un solo enfoque sino a varios. En relación con el enfoque, la declaración afirma:

La justicia restaurativa es una forma de atender a los niños (as) y adolescentes que están en conflicto con la ley que contribuye a la reintegración del niño (a) a la sociedad y lo(a) apoya a asumir un rol constructivo dentro de la sociedad. Toma seriamente la responsabilidad del niño(a) y al hacerlo, permite fortalecer el respeto y entendimiento del niño(a) respecto de los derechos humanos y las libertades fundamentales de los demás, en especial de la víctima y otros miembros afectados de la comunidad. La justicia restaurativa es un enfoque que promueve el sentido de dignidad y valor del niño (a). (Declaración de Lima sobre Justicia Juvenil Restaurativa, 2009, p.4).

Respecto de lo dispuesto sobre las reglas de su uso, se cita la Resolución 2002/12 del Consejo Económico y Social de las Naciones Unidas, principios básicos para los programas de justicia restaurativa en lo penal, donde se dice:

La justicia juvenil restaurativa debe emplearse solamente cuando exista evidencia suficiente para acusar al menor agresor, y cuando se cuente con el consentimiento libre y voluntario de la víctima y del agresor. Se debe permitir que el agresor y la víctima puedan retirar dicho consentimiento en cualquier momento durante el proceso de justicia restaurativa. Se debe llegar a acuerdos en forma voluntaria y éstos deben contener únicamente 
obligaciones razonables y proporcionales. Ni la víctima ni el agresor juvenil deben ser coaccionados ni inducidos por medios injustos a participar en el proceso restaurativo ni a aceptar los resultados restaurativos. Deben tomarse en consideración las discrepancias que conducen a desequilibrios en el poder, así como las diferencias culturales entre las partes. (Resolución 2002/12 de 2002)

La administración de justicia juvenil debe tener en el modelo restaurativo su mejor expresión: El reto institucional no puede ser inferior a las expectativas de restablecer los derechos y reparar la relación social entre el infractor adolescente y la víctima, a fin de mejorar las condiciones de vida en la sociedad. Por consiguiente, es necesario descongestionar la actividad judicial, actualmente atraviesa inconvenientes en la operación del SRPA y no es prenda de garantía para los derechos de los adolescentes. Las diferentes experiencias de Estados que aplican elementos del modelo restaurativo demuestran su efectividad. La adopción del modelo de justicia restaurativa en Colombia, requiere de una reformulación estructural en todos los niveles de gobierno, encaminada a buscar efectividad en la garantía de los derechos y prevenir la delincuencia juvenil.

\section{Fases de implementación y problemas del SRPA}

El documento CONPES 3629 (2009) se convierte en un mecanismo de información del Estado, en tanto le permite tomar medidas frente a la operatividad del sistema, realizar observaciones relacionadas con las fases de implementación gradual en los distritos judiciales del país y determinar qué entidades conforman el sistema como sus problemas principales agrupados en 5 ejes particulares.

El Decreto 3840 de 2008 (Decreto 3840, 2008) dispuso en su momento que una vez revisada las apropiaciones presupuestales para la implementación del SRPA, era necesario aumentar una nueva fase para la operatividad del sistema, el cual quedó así: 
Fases de implementación del srpa

\begin{tabular}{|c|c|c|}
\hline FASE & DISTRITOS JUDICIALES & FECHA \\
\hline I & Bogotá y Cali & $15 / 03 / 2007$ \\
\hline II & Armenia, Manizales, Pereira, Buga y Medellín & $01 / 04 / 2008$ \\
\hline III & Tunja, Santa Rosa de Viterbo y Popayán & $01 / 10 / 2008$ \\
\hline IV & Cúcuta, Pamplona, Bucaramanga y San Gil & $15 / 12 / 2008$ \\
\hline V & $\begin{array}{c}\text { Antioquia, Cundinamarca, Ibagué, Neiva, Barranquilla, } \\
\text { Santa Marta, Cartagena, Riohacha, Sincelejo, } \\
\text { Montería y Valledupar. }\end{array}$ & $01 / 06 / 2009$ \\
\hline VI & $\begin{array}{c}\text { San Andrés, Villavicencio, Pasto, Quibdó, Yopal, } \\
\text { Florencia y Arauca. }\end{array}$ & $01 / 12 / 2009$ \\
\hline
\end{tabular}

Fuente: Decreto 3840 de 2008

Como se expresa en este cuadro, la aplicación del sistema de manera gradual en los diferentes distritos judiciales tiene como consecuencia una obligación para su articulación con los sectores e instituciones públicos y privados. Asi mismo, temas trascendentales como: el presupuesto, capacitación, infraestructura y bases de información que generen controles y evaluaciones del mismo. Estos siguen siendo elementos cruciales en su efectividad como garantía de derechos de los adolescentes.

\section{Entidades que conforman el SRPA}

El documento CONPES 3629 (2009) generó avances, marcó el sustento normativo interno y externo para la implementación del sistema, igualmente, se convirtió en una regla de interpretación administrativa y judicial para la operatividad del sistema. Además, enunció qué entidades lo conforman. En los apartes del CONPES 3629 (2009) se resalta lo siguiente:

El Sistema de Responsabilidad Penal para Adolescentes, SRPA, implica dos procesos paralelos y complementarios, un proceso judicial y uno de restablecimiento de sus derechos. Su garantía y protección integral implica un sistema complejo, integrado por instituciones del orden nacional y territorial, bajo el principio de corresponsabilidad entre la Familia, la Sociedad y el Estado. Entre las entidades que hacen parte del SRPA se encuentran: la Policía Nacional (Infancia y Adolescencia), la Fiscalía General de la Nación (Cuerpo Técnico especializado), el Instituto Nacional de Medicina Legal y Ciencias Forenses, la Rama Judicial - (Consejo Superior 
de la Judicatura y jueces penales para adolescentes, con funciones de garantías y de conocimiento), la Defensoría del Pueblo (defensores públicos del Sistema Nacional de Defensoría Pública y Delegada para los Derechos de la Niñez, la Juventud y las Mujeres), la Defensoría de Familia del ICBF, Comisarías de Familia, Inspecciones de Policía, el Instituto Colombiano de Bienestar Familiar, las Entidades Territoriales (alcaldías y gobernaciones) y demás entidades que conforman el Sistema Nacional de Bienestar Familiar, SNBF. (CONPES 3629, 2009, p.18)

Atendiendo a lo dispuesto en el documento CONPES 3629 (2009), a la ley de infancia y adolescencia, jurisprudencia, elementos doctrinarios y académicos que han aportado argumentos de importancia para el sistema, se concluye que las entidades de orden nacional y territorial deben establecer en su interior dependencias con funciones específicas y con amplia cobertura que responda a las necesidades de infraestructura. Todo esto para reforzar la capacitación en legislación de menores a sus funcionarios, actualizarlos bajo la perspectiva de la protección integral y cerrar el capítulo de la situación irregular, donde aún convive el pensamiento de muchos funcionarios. Tales circunstancias permitirán que un SRPA complejo en Colombia, dadas las situaciones que lo rodean, tenga elementos para ser efectivo y se convierta en un instrumento de formulación para una verdadera política de responsabilidad penal para adolescentes en Colombia.

\section{Causas principales del problema de implementación del SRPA}

Los cambios de paradigma se convierten en una dificultad cuando no se asumen por la mayoría de los funcionarios de las entidades públicas, lo que incide en la falta de disposición para hacer parte de los cambios estructurales, es el caso particular de la implementación del SRPA. Persisten servidores públicos asumiendo una postura negativa frente a lo que predica la ley 1098 de 2006 (ley 1098, 2006), circunstancia que afecta la atención y restablecimiento de derechos en el marco de la justicia restaurativa, elemento crucial en el SRPA.

Según el documento CONPES 3629 (2009) se evidencian causas principales del problema central. Sobre esto manifiesta: 
Las causas principales del problema central se han agrupado en cinco (5) ejes particulares, que implican la aplicación del principio de corresponsabilidad y están relacionados con: i) los programas y servicios implementados enfrentan retos de cobertura, calidad y pertinencia; ii) insuficiente recurso humano especializado, del orden nacional y territorial, para operar el SRPA; iii) limitada articulación y coordinación, sectorial y territorial, de las entidades que hacen parte del SRPA y de éste con otros sistemas garantes de los derechos de los adolescentes; iv) escasa apropiación de las responsabilidades de las entidades territoriales en el SRPA y ejercicio efectivo del principio de corresponsabilidad y v) ausencia de un sistema de información que permita hacer compatible la información de las entidades del SRPA. (CONPES 3629, 2009, p.48)

Identificadas las causas problemáticas y con miras a fortalecer el SRPA se vislumbra la necesidad de crear una red de articulación con cada una de las entidades que hacen parte del sistema, para construir mecanismos de seguimiento e indicadores que permitan evaluar si el sistema cumple con los fines propuestos.

Los programas y servicios que se han implementado desde el año de expedición del documento padecen problemas de cobertura, calidad y pertinencia, pese a los esfuerzos del Instituto Colombiano de Bienestar Familiar-ICBF, como coordinador del Sistema Nacional de Bienestar Familiar, al formular lineamientos técnicos en relación con las medidas y sanciones en el marco del SRPA, es menester la concurrencia y compromiso de las entidades territoriales para su efectividad.

La insuficiencia del recurso humano especializado es la causa problemática apremiante del sistema. Toda vez que la falta de capacitación, formación profesional en la materia, incapacidad de recursos financieros para la apertura de concursos públicos que provean cargos y contratar personal que ejerza funciones solo para el sistema, no hacen parte los puntos con alerta roja en la agenda pública del gobierno.

Además de la limitada articulación y coordinación sectorial y territorial de las entidades que hacen parte del SRPA y de éste con otros sistemas garantes de los derechos de los adolescentes, tal como se ha dejado sentado, es preocupación capital la falta de articulación de las instituciones. Debido a esto se expidió el Decreto 1885 de 2015 (Decreto 1885, 2015), el cual establece la creación del Sistema Nacional de Coordinación de Responsabilidad Penal 
de Adolescentes-. SNCRPA, con la finalidad de coordinar, evaluar y establecer parámetros para la operación del SRPA. Además, se crean 2 instancias de operación e intervención: una liderada por el Ministerio de Justicia con radio de acción amplio de seguimiento de la asignación de recursos para su funcionamiento, administración y promoción del diseño de políticas públicas. La otra, en cabeza del gobernador con el objetivo de tener una visual directa de la complejidad del sistema en la región (Decreto 1885, 2015).

Ante la escasa apropiación de las responsabilidades de las entidades territoriales en el SRPA y ejercicio efectivo del principio de corresponsabilidad, la Ley 1098 de 2006 en su artículo 204, responsables de las políticas públicas de infancia y adolescencia, dispone:

Son responsables del diseño, la ejecución y la evaluación de las políticas públicas de infancia y adolescencia en los ámbitos nacional, departamental, distrital y municipal, el Presidente de la República, los gobernadores y los alcaldes. Su incumplimiento será sancionado disciplinariamente como causal de mala conducta. La responsabilidad es indelegable y conlleva a la rendición pública de cuentas.

En el nivel territorial se deberá contar con una política pública diferencial y prioritaria de infancia y adolescencia que propicie la articulación entre los Concejos Municipales, Asambleas y Congreso Nacional, para garantizar la definición y asignación de los recursos para la ejecución de la política pública propuesta. (Ley 1098, 2006, art. 204)

En lo que concierne a las entidades territoriales, la efectividad del principio de corresponsabilidad exige una mayor atención, al asumir responsabilidades para la infancia y adolescencia, so pena de incurrir disciplinariamente en causal de mala conducta. La realidad de los gobiernos locales demuestra falta de atención a una problemática que va en ascenso.

Debido a la ausencia de un sistema de información que permita hacer compatible la información de las entidades del SRPA nace la necesidad de formular un sistema de información, donde las diferentes entidades que lo integran puedan alimentarlo, convirtiéndolo en una herramienta de análisis, seguimiento y evaluación. Al respecto, hay que reconocer el avance evidenciado en el texto del Decreto 1885 de 2015, Artículo 5, Numeral 4: “coordinar con los actores pertinentes la formulación del sistema único de información del SRPA” 
(Decreto 1885, 2015, art. 5, numeral 4). En la actualidad y con fundamento en el precepto legal es indispensable apropiar los recursos financieros para el funcionamiento del sistema único de información.

\section{Caso Palmira}

El municipio de Palmira no es ajeno a la situación expuesta, puesto que en la formulación, discusión y aprobación de sus últimos planes de desarrollo 2012-2015 y 2016-2019 no hay una política o programa integral que ponga en evidencia su responsabilidad con los menores en conflicto con la ley penal. Esta es una situación por resolver en el ámbito municipal y que actualmente espera una resolución oportuna.

El SRPA en Palmira funciona a través de un convenio de 5 municipios: Pradera, Florida, Candelaria, Cerrito y Palmira. Donde cada uno de los miembros se compromete a hacer un aporte financiero anual de $\$ 29.250 .000$ para contribuir al funcionamiento del sistema y el desarrollo de los programas establecidos. Palmira funciona como sede principal del SRPA, a través del Centro de Responsabilidad Penal para Adolescentes-CESPA, es decir, aquellos casos de niños, niñas y adolescentes infractores de Pradera, Florida, Candelaria y Cerrito son debidamente tramitados y judicializados en Palmira.

Sin embargo, actualmente los municipios de Florida, Cerrito y Pradera presentan una mora frente a estos aportes de 4, 2 у 1 año respectivamente para un total de $\$ 204.750 .000$. Esta es una de las principales causas del ineficaz funcionamiento de este convenio, pues las partes no cumplen con las obligaciones pactadas, lo que desemboca en el aumento anual y gradual de la criminalidad juvenil en Palmira e incluso en los demás municipios. El objeto del convenio no se está cumpliendo, la inversión en programas y la metodología para la ejecución de los mismos tampoco está dando los resultados esperados, por tanto sería conveniente buscar otras alternativas para mitigar la delincuencia juvenil en Palmira y el hecho de formular una política pública para el niño, niña y adolescente infractor se ha convertido en una imperiosa necesidad.

Según el informe presentado por la Secretaría de Integración Social y el ICBF- centro zonal Palmira al Concejo Municipal, el total de inversión anual para niños y niñas en materia de primera infancia en el municipio de Palmira es de $\$ 9.691 .558 .346$, para atender alrededor de 5.309 niños y niñas exclusivamente menores de 5 años. Dicho rubro está destinado a los hogares 
comunitarios, centros de desarrollo infantil y hogares infantiles (Informe Secretaría de Integración Social, 2016). Sin embargo, actualmente no existe una inversión que se encuentre destinada al cuidado del menor en todas las etapas de su desarrollo, esto es, desde la primera infancia hasta los 18 años, donde cumple su mayoría de edad, a fin de garantizar una protección integral. Aún más, es preocupante que a la fecha no existe en el municipio de Palmira una política destinada a la prevención, sanción, reorientación y rehabilitación del adolescente infractor.

En Palmira, actualmente existen deficiencias en la capacidad del recurso humano para prestar los servicios al SRPA, de ahí que sea insuficiente para tratar la gran cantidad de casos que se presentan a diario. Los adolescentes infractores no pueden ser debidamente judicializados con la garantía de sus derechos, lo que tiene como consecuencia que muchos deban ser dejados en libertad, porque no hay un lugar donde puedan cumplir su respectiva sanción o tratamiento, pues los que existen ya han alcanzado su máximo de cupos. Además no se tienen datos estadísticos sobre la ocupación del adolescente infractor, la ocupación de sus padres, el núcleo vivencial, el tipo de arma utilizada en el delito y el lugar del hecho punible. Factores que son de suma importancia para efectuar un programa de mitigación en los casos de delincuencia juvenil.

Generalmente, la reincidencia de los jóvenes infractores se da en aquellos que han ingresado por delitos que la Fiscalía considera menores y que no ameritan sanción. Estos terminan entonces siendo reintegrados a su medio familiar y, posteriormente, ingresan nuevamente al sistema de responsabilidad penal con un delito de mayor gravedad, porque no se hace ningún tipo de seguimiento a cada caso específico. Por estas causas y las demás expuestas a lo largo del presente trabajo se hace necesario generar conciencia en el gobierno local, con la participación de diferentes actores, para que formulen una política pública del adolescente en conflicto con la Ley penal en el municipio de Palmira. Sumado a la anterior aseveración, se puede concluir que el SRPA en Palmira pasa por una crisis institucional, originada por dos instancias: una nacional a través de las directrices del Consejo Superior de la Judicatura y otra local, al no existir conciencia colectiva del gobierno municipal para enfrentar la situación de delincuencia juvenil en la ciudad. Es importante mencionar ambas crisis para mayor claridad.

En el orden nacional, el Consejo Superior de la Judicatura, sala administrativa, mediante acuerdo No. PSAA15-10402 del 29 de octubre de 
2015 (Acuerdo No. PSAA15-10402 de 2015) se crean con carácter permanente, trasladan y transforman unos despachos judiciales y cargos en todo el territorio nacional. Del acto administrativo en mención, en su aplicación se evidencia una grave afectación a la finalidad de carácter especial del SRPA, al considerar del recurso mínimo para atender la alta demanda y las capacidades que exige el sistema del personal que asumen el conocimiento de la conductas antijurídicas, afectando tal vez gran parte del territorio nacional.

Concerniente al municipio de Palmira, que puede ser un reflejo de la situación nacional, antes del acuerdo del Consejo Superior de la Judicatura contaba igualmente con limitaciones de personal, así:

- 1 Juez de responsabilidad penal para adolescentes con funciones de control de garantías.

- 1 Juez de responsabilidad penal para adolescentes con funciones de conocimiento.

- 1 Fiscal de SRPA.

- 2 Defensores de Familia (1 de garantías y otro de conocimiento).

- 4 Defensores del pueblo.

Como se ha discutido, el poco personal del SRPA se desborda ante la alta demanda de criminalidad juvenil en la ciudad. En ese momento en crisis y sin respuesta del ente coordinador del SNBF, instituciones oficiales en todos sus órdenes y gobierno local. Pese a ello, se agrava la situación con la manifestación del Consejo Superior de la Judicatura, que no da respuestas conforme a la integralidad del sistema, lo sigue limitando y transforma las funciones de los despachos judiciales, particularmente los jueces de familia. Estos, ante su congestión judicial, ahora deben asumir doble función: la de familia por ley y las funciones de conocimiento del SRPA, de este modo, pierden completamente el norte del modelo propuesto por las disposiciones internacionales, por la Constitución Nacional, por la Ley de infancia y adolescencia y demás. La modificación obedece a la siguiente estructura, con la que funcionan actualmente:

- 1 Juez de responsabilidad penal para adolescentes con funciones de control de garantías.

- 1 Juez promiscuo de familia con funciones de conocimiento para el SRPA.

- 1 Fiscal de SRPA.

- 2 Defensores de Familia (1 de garantías y otro de conocimiento).

- 4 Defensores del pueblo. 
La justificación sin fines integrales, protección de los derechos de los adolescentes en el marco de justicia restaurativa como ideal, según el Consejo Superior de la Judicatura es consecuencia de los factores económicos, es decir, de las asignaciones presupuestales para la racionalidad del ejercicio de la rama judicial, una realidad innegable en Colombia que afecta de manera directa el ideal propuesto para un sector de población vulnerable.

\section{Conclusión}

La armonía entre la Convención sobre derechos del niño (1989) y la Constitución Política de Colombia de 1991 (Const., 1991) es el punto de partida para entender al adolescente como sujeto de derechos fundamentales y no como objeto de medidas tutelares del Estado. Es por esta razón que se debe garantizar el cumplimiento de sus derechos como resultado de los fines esenciales del Estado con miras a transitar de un sistema tutelar a uno garantista.

Los diferentes tratados internacionales que se aprobaron para conceder derechos específicos a los niños por su condición física, sicológica y demás, fueron el origen del sistema de normas para este sector de la población que hoy convive en los ordenamientos jurídicos internos del mundo. Su influencia en Colombia se refleja en la Ley de Infancia y Adolescencia, leyes, decretos y programas que se expidieron para dotar un sistema de responsabilidad penal para adolescentes, al cual pertenecen varias instituciones oficiales y privadas con carácter especializado, cuya función es rehabilitar, resocializar y reparar el daño en el marco de la justicia restaurativa.

La anterior descripción del SRPA permite una mejor comprensión de su funcionamiento desde su origen y desarrollo en el ordenamiento jurídico colombiano, al mismo tiempo refleja que el grupo poblacional de los adolescentes, en su mayoría, son carentes de servicios sociales del Estado y figuras familiares inestables, no observados en muchos aspectos por la sociedad. El resultado de esto es su participación en conductas delictivas sin posibilidad de un retorno social cercano, dadas las condiciones actuales del sistema de responsabilidad penal para adolescentes en Colombia, tal como se expuso en el municipio de Palmira que sirve de referente. Pese a las aproximaciones normativas, jurisprudenciales y demás programas que han regulado el SRPA, es indispensable la cohesión social, es decir, la articulación legal de sus entidades responsables, concientizadas del compromiso que exige la prevención y protección del adolescente en riesgo de llegar al campo delincuencial y de aquellos que ya han incurrido en ilicitudes. 


\section{Referencias bibliográficas}

Constitución Política de Colombia. (1991). Legis.

Corte Constitucional. Sala Plena (2008). Bogotá D.C. Sentencia C-740 del 23 de Julio de 2008. MP: Jaime Araujo Renteria.

Corte Constitucional. Sala Plena (2001). Bogotá D.C. Sentencia C-839 del 9 de Agosto de 2001. MP: Marco Gerardo Monroy Cabra.

Corte Constitucional. Sala Plena (2005). Bogotá D.C. Sentencia C-979 del 26 de Septiembre de 2005. MP: Jaime Cordoba Triviño.

Departamento Nacional de Planeación- DNP e Instituto Colombiano de Bienestar Familiar- ICBF. (s. f.). Guía para Alcaldes: marco para las políticas públicas y lineamientos para la planeación del desarrollo de la infancia y la adolescencia en el municipio. TC Impresores.

Informe centro de responsabilidad para adolescentes. (2016). Municipio de Palmira.

Marshall, T. (1998). Restorative justice. United States of America: NCJRS Library. Recuperado de: http://www.ncjrs.gov/App/publications/abstract.aspx?ID=178049

Naciones Unidas Derechos Humanos. (1948). Declaración Universal de los Derechos Humanos, adoptada y proclamada por la Asamblea General de las Naciones Unidas en su Resolución 217 A (III), 10 de diciembre de 1948. Recuperado de: https//www. un.org/es/universal-declaration-humanrights/

Naciones Unidas Derechos Humanos. (1989). Convención sobre los Derechos del Niño, adoptada y abierta a la firma y ratificación por la Asamblea General en su Resolución 44/25, 20 de noviembre de 1989. Recuperado de: https://www.ohchr. org/sp/professionalinterest/pages/crc.aspx

Naciones Unidas Derechos Humanos. (1966). Pacto Internacional de Derechos Civiles y Políticos. Adoptado y abierto a la firma, ratificación y adhesión por la Asamblea General en su Resolución 2200 A (XXI), 16 de diciembre de 1966. Recuperado de: https://www.ohchr.org/SP/professionallinterest/Pages/CCPR.aspx

Naciones Unidas Derechos Humanos.(1966). Pacto de derechos económicos, sociales y culturales. Adoptado y abierto a la firma, ratificación y adhesión por la Asamblea General en su Resolución 2200 A (XXI), 16 de diciembre de 1966. Recuperado de: https://www.ohchr.org/SP/professionallinterest/Pages/CCPR.aspx

Naciones Unidas Derechos Humanos.(1985). Reglas mínimas de las Naciones Unidas para la administración de justicia de menores "Reglas de Beijing". Adoptadas por la Asamblea General en su Resolución 40/33, 28 de noviembre de 1985. Recuperado de: http://www.cidh.oas.org/Ninez/pdf\%20files/Reglas\%20de\%20Beijing.pdf

Naciones Unidas Derechos Humanos.(1990). Reglas de las Naciones Unidas para la protección de los menores privados de la libertad. Adoptadas por la Asamblea General en su Resolución 45/113, 14 de diciembre de 1990. Recuperado de: http://www.acnur.org/fileadmin/Documentos/BDL/2002/1423.pdf?file=fileadmin/ Documentos/BDL/2002/1423

Naciones Unidas Derechos Humanos.(1990). Directrices de las Naciones Unidas para prevención de la delincuencia juvenil "Directrices de la RIAD". Adoptadas y proclamadas por la Asamblea General en su Resolución 45/112, 14 de diciembre de 1990. Recuperado de: https://www.ohchr.org/sp/professionallinterest/pages/ preventionofjuveniledelinquecy.aspx 
Naciones Unidas Derechos Humanos.(1986). Declaración sobre los principios sociales y jurídicos relativos a la protección y el bienestar de los niños, con particular referencia a la adopción y la colocación en hogares de guarda, en los planos nacional e internacional. . Adoptada por la Asamblea General en su Resolución 41/85, 3 de diciembre de 1986. Recuperado de: https://www.bienestaryproteccioninfantil.es/ fuentes1.asp?sec $=13 \&$ subs $=16 \&$ cod $=634 \&$ page $=$

Primer Congreso Mundial de Justicia Restaurativa. (2009). Declaración de Lima sobre Justicia Juvenil Restaurativa. Recuperado de: https://tdh-latam.org/wp-content/ uploads/2018/03/Declaracion_de_Lima.pdf

República de Colombia. Departamento Nacional de Planeación. Consejo Nacional de Política Social y Económica (2009). Sistema de Responsabilidad Penal para Adolescentes: SRPA. Política de Atención al Adolescente en Conflicto con la Ley. Conpes 3629 de 2009. Recuperado de: https://www.icbf.gov.co/sites/default/files/ conpes-3629-srpa-pdf

República de Colombia. Presidente de la República. (27 de noviembre de 1989). Por la cual se expide el Código del Menor. Decreto 2737 de 1989. DO No. 39.080 de 27 de noviembre de 1989. Recuperado de http: // www. secretariasenado.gov.co. / senado/basedoc/Decreto_2737_1989.html

República de Colombia. Presidente de la República. (21 de septiembre de 2015). Por el cual se crea el Sistema Nacional de Coordinación de Responsabilidad Penal para Adolescentes (SNCRPA) y se dictan otras disposiciones. Decreto 1885 de 2015. DO: No. 49.642 de 21 de septiembre de 2015. Recuperado de http: // www. icbf.gov.co. /cargues/avance/docs/decreto_1885_2015.htm

República de Colombia. Presidente de la República. (11 de diciembre de 2015). Por el cual se reglamenta la prestación del servicio educativo en el marco del Sistema de Responsabilidad Penal para Adolescentes y se adiciona al Decreto 1075 de 2015 Único Reglamentario del sector educación. Decreto No. 2383 de 2015. Falta DO: 49723 de 11 de diciembre de 2015. Recuperado de http: // www. mineducacion. gov.co. /1759/w3-article-382088.htm?_noredirec $=1$

República de Colombia. Congreso de la República. (24 de Julio de 2000). Por medio del cual se expide el Código Penal. Ley 599 de 2000. DO: 44097 del 24 de julio de 2000. Recuperado de http: // www. secretariasenado.gov.co. /senado/basedoc/ ley_599_2000.html

República de Colombia. Congreso de la República. (1 de septiembre de 2004). Por medio del cual se expide el Código de Procedimiento Penal. Ley 906 de 2004. DO: 45658 de septiembre 1 de 2004. Recuperado de http: // www. secretariasenado. gov.co./senado/basedoc/ley-906-2004.html

República de Colombia. Congreso de la República. (8 de Noviembre de 2006). Por la cual se expide el Código de Infancia y Adolescencia. Ley 1098 de 2006. DO: 46.446 del 8 de noviembre de 2006. Recuperado de http: // www. secretariasenado. gov. co. /senado/basedoc/ley_1098_2006.html

República de Colombia. Congreso de la República. (24 de Junio de 2011). Por medio de la cual se reforma el Código Penal, el Código de Procedimiento Penal, el Código de Infancia y Adolescencia, las reglas sobre extinción de dominio y se dictan otras disposiciones en materia de seguridad. Ley 1453 de 2011. DO: 48110 de junio 24 de 2011. Recuperado de http: // www. secretariasenado. gov.co. /senado/basedoc/ ley_1453_2011.html 
República de Colombia. Congreso de la República. (16 de Junio de 2011). Por la cual se expide el Plan Nacional de Desarrollo, 2010-2014. Ley 1450 de 2011. DO: 48.102 de 16 de junio de 2011. Recuperado de http: // www. secretariasenado.gov.co. / senado/basedoc/ley_1450_2011.html

República de Colombia. Presidente de la República. (30 de Septiembre de 2008). Por el cual se modifica el artículo 2 del Decreto 4652 del 27 de diciembre de 2006, modificado por los Decretos 1494 del 4 de mayo de 2007 y 3951 del 12 de octubre de 2007. Decreto 3840 de 2008. DO No. 47.128 de 30 de septiembre de 2008. Recuperado de http: // www. icbf.gov.co. /cargues/avance/docs/decreto_3840_2008.htm 